\title{
Nanoparticle albumin-bound paclitaxel combined with cisplatin as the first-line treatment for metastatic esophageal squamous cell carcinoma
}

This article was published in the following Dove Press journal:

OncoTargets and Therapy

24 May 2013

Number of times this article has been viewed

Yan Shi

Rui Qin

Zhi-Kuan Wang

Guang-Hai Dai

Department of Multimodality Therapy of Oncology, General Hospital of CPLA, Beijing, People's Republic of China
Correspondence: Guang-Hai Dai Department of Multimodality Therapy of Oncology, General Hospital of CPLA, No 28 Fuxing Road, Beijing, People's Republic of China

Tel/fax +86 I0 6693 727I

Email daigh60@sohu.com
Abstract: Esophageal cancer is a major health hazard in many parts of the world and is often diagnosed late. The objective of this study was to explore the efficacy and safety of nanoparticle albumin-bound paclitaxel (Nab-PTX) combined with cisplatin (DDP) in patients with metastatic esophageal squamous cell carcinoma (ESCC). Patients with histologically confirmed ESCC were treated with Nab-PTX $250 \mathrm{mg} / \mathrm{m}^{2}$ and DDP $75 \mathrm{mg} / \mathrm{m}^{2}$ intravenously on day 1, every 21 days. Evaluation was performed after every two cycles of therapy and the therapy was continued until disease progression or unacceptable toxicity. From April 2010 to December 2012, 33 patients were enrolled. Ten patients had recurrent and metastatic tumors after surgery and 23 patients were diagnosed with unresectable metastatic disease. Patients received a median of four cycles of therapy (ranging from two to six cycles). Twenty patients achieved partial response and nine patients achieved stable disease; no complete response was observed. The objective response rate was $60.6 \%$ and the disease control rate was $87.9 \%$. The median progression-free survival was 6.2 months (95\% confidence interval: 4.0 to 8.4 months) and the median overall survival was 15.5 months (95\% CI: 7.6 to 23.4 months). Only four patients experienced grade 3 adverse events, including vomiting, neutropenia, and sensory neuropathy. The most common adverse events were nausea/vomiting (81.8\%), neutropenia (63.6\%), leucopenia (48.5\%), anemia (24.2\%) and sensory neuropathy (24.2\%). In conclusion, the combination of Nab-PTX and DDP is a highly effective and well-tolerated first-line treatment in metastatic ESCC.

Keywords: esophageal squamous cell carcinoma, nanoparticle albumin-bound paclitaxel, chemotherapy, metastasis

\section{Introduction}

Esophageal cancer is one of the most common cancers, and is also a major cause of cancer-related mortality worldwide. ${ }^{1}$ Esophageal squamous cell carcinoma (ESCC) may be associated with a worse prognosis after surgery than esophageal adenocarcinoma. ${ }^{2}$ Due to few symptoms at the initial phase and the aggressive nature of esophageal cancer, advanced/metastatic cases with unresectable tumors and recurrent cases after resection are frequently observed. For those patients with unresectable esophageal tumor or metastatic disease, taxane- and platinum-based regimens, as well as fluoropyrimidine-based regimens, have been proven to be reasonable and effective first-line chemotherapy. ${ }^{3-5}$ However, the median survival is only $8-12$ months in patients with advanced/metastatic ESCC, regardless of which combined regimen is given, such as 5-fluorouracil (Fu) plus cisplatin (DDP)/oxaliplatin (OXA), ${ }^{3,6}$ or paclitaxel (PTX) or docetaxel (TXT) plus carboplatin/DDP. ${ }^{7,8}$ Recently, although tripledrug regimens, such as 5-Fu/capecitabine, DDP, and TXT, have shown some efficacy 
advantages for advanced/metastatic ESCC, their long-term outcome advantages are not obvious due to higher incidences of grade 3 or 4 toxicity. ${ }^{9-11}$ Therefore, it is very important to explore more effective but less cytotoxic regimens for systemic treatment to achieve consistent survival improvement in advanced/metastatic ESCC.

The $130 \mathrm{~nm}$ nanoparticle albumin-bound PTX (Nab-PTX [Abraxane]; Celgene Corporation, Summit, NJ, USA) is a novel, solvent-free PTX that uses albumin to deliver PTX, thus avoiding the need for solvents such as polyoxyethylated castor oil and ethanol. The solvents used for conventional taxanes can lead to serious toxicities such as hypersensitivity reaction and peripheral neuropathy, requiring premedication with steroid and antihistamine, ${ }^{12}$ and can limit drug amount and bioavailability. Thus, theoretically, the solvent-free Nab-PTX should be a more effective and less toxic reagent than conventional taxanes. Preclinical models suggest that Nab-PTX may reach tumors more efficiently with enhanced accumulation than solvent-based taxane. ${ }^{13}$ Clinical studies have shown that Nab-PTX is safe with increased objective response rate (ORR) and time to progression in metastatic breast cancer compared with solvent-based PTX and TXT, and great activity has also been shown in various other advanced solid tumors, including non-small-cell lung cancer (NSCLC) and pancreatic cancer. ${ }^{14-17}$ Therefore, Nab-PTX has been an alternative reagent for those cancers that could be treated with PTX or TXT. However, little is known about the safety and efficacy of Nab-PTX in combination with DDP in ESCC. The objective of this study was to explore the efficacy and toxicity of Nab-PTX combined with DDP as the first-line chemotherapy for patients with metastatic ESCC.

\section{Materials and methods Patients}

Patients with metastatic ESCC were enrolled in this study based on the following criteria: (1) histologically confirmed ESCC and classified as unresectable esophageal cancer with metastatic lesions or recurrent and metastatic ESCC after surgery; (2) age $<70$ years and a life expectancy of $>8$ weeks; (3) at least one measurable lesion for assessment by computed tomography (CT) or magnetic resonance imaging (MRI), and no prior radiotherapy or other local treatment for parameter lesions, including primary and metastatic lesions; (4) No prior chemotherapy for metastatic disease. Previous chemotherapy without taxane as adjuvant treatment is acceptable, if the adjuvant chemotherapy has been completed at least 6 months before entry into in this study; (5) an Eastern Cooperative Oncology Group performance status (ECOG PS) ${ }^{18}$ of $0-2$; (6) adequate hematological (absolute neutrophil count $\geq 1.5 \times 10^{9} / \mathrm{L}$, platelets $\geq 100 \times 10^{9} / \mathrm{L}$, and hemoglobin $\geq 9 \mathrm{~g} / \mathrm{dL}$ ), hepatic (total bilirubin $<1.5$-fold of the upper limit of normal value, aspartate aminotransferase and alanine aminotransferase $<$ 1.5-fold of the upper limit of normal value), and renal (blood urea nitrogen and serum creatinine $<$ the upper normal level) functions; (7) no other active malignancies.

This study was conducted according to the principles of the Declaration of Helsinki and International Conference on Harmonisation Good Clinical Practice guidelines. Written informed consent was obtained from all patients. Moreover, the protocol of study was reviewed and approved by the ethical board of CPLA General Hospital.

\section{Protocol treatment}

Nab-PTX was administered intravenously over 30 minutes at $250 \mathrm{mg} / \mathrm{m}^{2}$ without corticosteroid or antihistamine premedication, ${ }^{12}$ followed by DDP $75 \mathrm{mg} / \mathrm{m}^{2}$ administered intravenously for 2 hours on day 1, every 21 days. The rationale of dosing Nab-PTX was based on a Phase III study, in which $\mathrm{Nab}-\mathrm{PTX}$ was given at $260 \mathrm{mg} / \mathrm{m}^{2}$ every 3 weeks as a single agent for patients with metastatic breast cancer. ${ }^{15}$ In the current study, the dosage of Nab-PTX was reduced to $250 \mathrm{mg} / \mathrm{m}^{2}$ every 3 weeks due to combination with DDP. For patients experiencing intolerable toxicities, treatment was to be interrupted for up to 42 days, allowing them to recover from the adverse events. When Common Toxicity Criteria (CTC) grade 3/4 symptoms resolved, chemotherapy was reduced to $75 \%$ of the previous dose. Any patient requiring $>42$ days of recovery time or more than two dose reductions due to toxicity was to be discontinued from the study. In general, treatment continued until disease progression, unacceptable toxicity, two cycles after maximal response, or a maximum of eight cycles, at the discretion of the treating physician.

\section{Efficacy and toxicity evaluation}

Baseline tumor measurements were taken no more than 14 days before treatment. The objective of this study was to determine the response rate as well as safety of Nab-PTX in combination with DDP in patients with metastatic ESCC. Therefore, the primary end point was ORR. The secondary end points were disease control rate (DCR), progression-free survival (PFS), overall survival (OS), and safety. Evaluation of tumor response was performed with the same imaging technique that was used at baseline every two cycles of therapy according to Response Evaluation Criteria in Solid Tumors (RECIST), ${ }^{19}$ and every 12 weeks within the follow-up period until disease progression. 
The safety measures, including adverse events, physical examinations, and clinical laboratory tests (hematology, blood chemistry, hepatic functions, and renal functions) were completed before each cycle. Toxicities were graded using version 3.0 of the National Cancer Institute Common Toxicity Criteria. ${ }^{20}$

\section{Statistical analysis}

Descriptive statistics were used for patient characteristics, treatments, and safety evaluation. Mean values and standard deviations (SDs) were provided for continuous end points and frequency and percentage distributions were provided for discrete data. ORR, DCR, and their two-sided $95 \%$ confidence intervals (CIs) were calculated. PFS was defined as the duration from the initial treatment day of the protocol until the day of disease progression, or until the last follow-up day, or until death. Similarly, OS was defined as the duration from the initial treatment day of the protocol until death due to any cause or until the last follow-up day. PFS and OS were estimated using the Kaplan-Meier method and their medians, along with two-sided $95 \%$ CIs, were calculated. All analyses were performed using the SPSS software package (v 16.0; IBM Corporation, Armonk, NY, USA).

\section{Results}

\section{Patient characteristics}

A total of 33 patients with metastatic ESCC were enrolled in this study between April 2010 and December 2012. The baseline patient characteristics are summarized in Table 1. Only two patients had received adjuvant chemotherapy without taxane agent 12 months before entering this study. The predominant sites of metastatic disease were distant lymph nodes in 31 cases (93.9\%) and organ metastases in 16 cases $(48.5 \%)$.

\section{Efficacy and survival}

A total of 138 cycles of Nab-PTX in combination with DDP were administered. The median number of cycles of chemotherapy per patient was four (ranging from two to six cycles). Twenty-six (78.8\%) of 33 enrolled patients received at least four cycles of chemotherapy. Of the 33 patients, no complete response (CR) was observed, whereas 20 patients achieved partial response (PR) and nine patients achieved stable disease (SD). Only four patients had progressive disease (PD). The ORR (CR + PR) was $60.6 \%$ and the DCR $(\mathrm{CR}+\mathrm{PR}+\mathrm{SD})$ was $87.9 \%$ (Table 2). The median PFS was 6.2 months (95\% CI: 4.0 to 8.4 months) and median OS was 15.5 months (95\% CI: 7.6 to 23.4 months) (Figures 1 and 2).
Table I Baseline characteristics of enrolled patients $(n=33)$

\begin{tabular}{ll}
\hline Characteristic & Number (\%) \\
\hline Age (years) & 56 \\
Median & $43-70$ \\
Range & \\
Sex & $30(90.9)$ \\
Male & $3(9.1)$ \\
Female & \\
ECOG performance status & $22(66.7)$ \\
0 & $11(33.3)$ \\
I & \\
Patient status & $10(30.3)$ \\
Recurrence/metastases after surgery & $23(69.7)$ \\
Unresectable tumor with metastases & \\
Differentiation & $4(12.1)$ \\
Good & $13(39.4)$ \\
Moderate & $14(42.4)$ \\
Poor & $2(6.1)$ \\
Unknown & \\
Number of metastatic sites & $12(36.4)$ \\
I & $15(45.5)$ \\
2 & $6(18.2)$ \\
$\geq 3$ & $10(30.3)$ \\
Site of metastatic disease & $5(15.2)$ \\
Lung & $5(15.2)$ \\
Liver & $31(93.9)$ \\
Bone & $2(6.1)$ \\
Distant lymph nodes & \\
Other organ metastases & \\
\hline
\end{tabular}

Abbreviation: ECOG, Eastern Cooperative Oncology Group.

\section{Toxicity}

The hematologic and nonhematologic toxicities associated with the combined chemotherapy are summarized in Table 3. In general, the regimen of Nab-PTX combined with DDP was well tolerated and most adverse events were mild. No unexpected toxicities or treatment-related deaths were observed during this study. Twenty-nine (87.9\%) patients were reported as having at least one adverse event during the study, and only four patients experienced grade 3 adverse events, including vomiting (male, 49 years, six cycles), neutropenia (two cases, both male and four cycles, 70 and 56 years) and sensory neuropathy (male, 60 years, four cycles). The most common adverse events were nausea/ vomiting (81.8\%), neutropenia (63.6\%), leucopenia (48.5\%), anemia $(24.2 \%)$, and sensory neuropathy $(24.2 \%)$. Four patients $(12.1 \%)$ experienced dose reductions due to adverse events during their therapy.

\section{Discussion}

For patients with incurable advanced/metastatic esophageal cancer who experience unresectable regional relapse or distant metastasis after esophagectomy, there 
Table 2 Response for patients treated with Nab-PTX and DDP

\begin{tabular}{|c|c|c|}
\hline Response & Number (\%) & $\begin{array}{l}95 \% \text { confidence } \\
\text { interval }\end{array}$ \\
\hline Complete response & - & - \\
\hline Partial response & $20(60.6)$ & $48.5-81.8$ \\
\hline Stable disease & $9(27.3)$ & $12.1-45.4$ \\
\hline Progressive disease & $4(12.1)$ & $3.0-30.3$ \\
\hline Objective response rate & $20(60.6)$ & $48.5-81.8$ \\
\hline Disease control rate & $29(87.9)$ & 69.7-97.0 \\
\hline
\end{tabular}

are few regimens recommended as first-line therapy. In the absence of adequately powered Phase III trials for many years, the major regimens listed in the National Comprehensive Cancer Network Guideline of esophageal cancer are mainly derived from advanced gastric cancer Phase III trials including lower esophageal and esophagogastric junction (EGJ) cancer. ${ }^{21,22}$ However, the main histological cancer type in advanced gastric cancer, lower esophageal, and EGJ cancer is adenocarcinoma and not SCC; ${ }^{23} \mathrm{SCC}$ is different from adenocarcinoma of the esophagus in biological characteristics, drug sensitivity, and prognosis. ${ }^{2,24,25}$ Thus, it is important to find effective regimens for metastatic ESCC. It is reported that taxanebased regimens have demonstrated high clinical activities and survival advantages in metastatic ESCC, ${ }^{26-31}$ and it was hypothesized that replacing PTX with solvent-free Nab-PTX might provide even better clinical benefits to patients with metastatic ESCC. Therefore, in this study, a novel formulation of Nab-PTX was explored for combination with DDP as a first-line regimen for patients with metastatic ESCC.

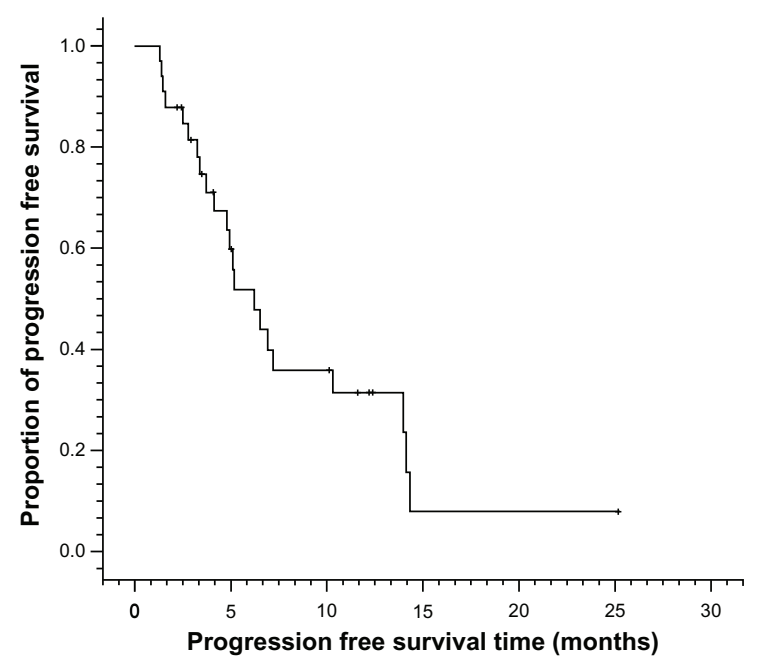

Figure I Progression-free survival curves for metastatic esophageal cancer patients treated with nanoparticle albumin-bound paclitaxel plus cisplatin $(n=33)$.

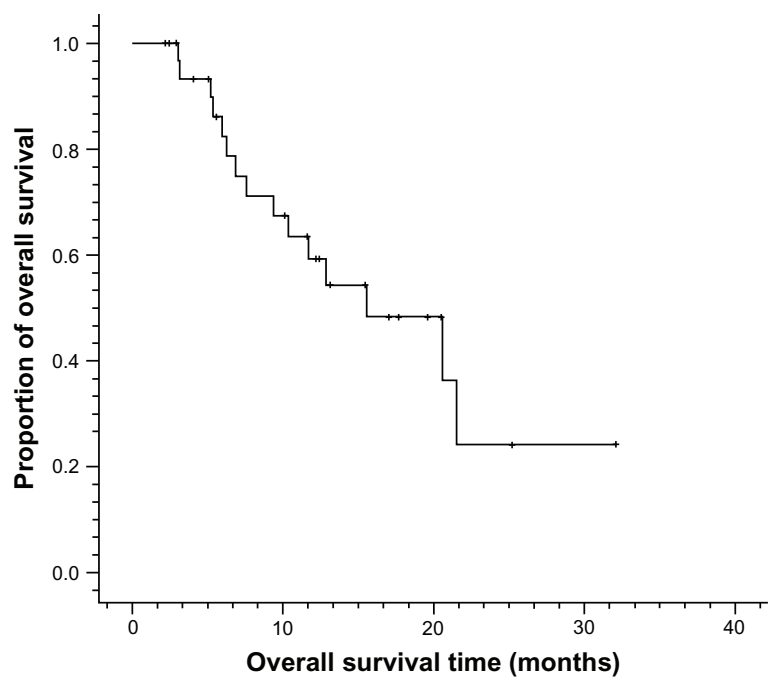

Figure 2 Overall survival curves for metastatic esophageal cancer patients treated with nanoparticle albumin-bound paclitaxel plus cisplatin $(n=33)$.

In the 33 patients treated in this study, the regimen of Nab-PTX plus DDP showed promising efficacy, with an ORR of $60.0 \%$, a DCR of $87.9 \%$, a median PFS of 6.2 months, and a median OS of 15.5 months. This regimen was also well tolerated, and toxicity was manageable. The most common toxicity related to DDP was nausea/ vomiting, as expected. Hematological toxicity, especially myelosuppression, was slighter compared with previous studies on taxane-based regimens in esophageal cancer. ${ }^{5,26}$ Only four patients experienced grade 3 adverse events. Although this study had no control arm, the results were consistent with other previously reported studies ${ }^{26-36}$ in metastatic ESCC, which are summarized in Table 4. Between 2005 and 2011, there were only 11 studies on first-line chemotherapy in metastatic ESCC.The most frequently investigated regimens were PTX-based, TXTbased, platinum-based, and 5-Fu/capecitabine-based in those studies, with ORR ranging from $13 \%-75 \%$, PFS ranging from 3.6 months to 7.0 months, and OS ranging

Table 3 Toxicity $(n=33)$

\begin{tabular}{lllll}
\hline $\begin{array}{l}\text { Adverse event, } \\
\text { N (\%) }\end{array}$ & Grade I & Grade 2 & Grade 3 & Grade 4 \\
\hline Leucopenia & $7(2 \mathrm{I} .2)$ & $8(24.2)$ & $\mathrm{I}(3.0)$ & - \\
Neutropenia & I $3(39.4)$ & $7(2 \mathrm{I} .2)$ & $\mathrm{I}(3.0)$ & - \\
Thrombocytopenia & $\mathrm{I}(3.0)$ & - & - & - \\
Anemia & $8(24.2)$ & - & - & - \\
Sensory neuropathy & $5(15.2)$ & $2(6 . \mathrm{I})$ & $\mathrm{I}(3.0)$ & - \\
Bilirubin & $2(6.1)$ & $\mathrm{I}(3.0)$ & - & - \\
Nausea/vomiting & $\mathrm{I} 5(45.5)$ & $\mathrm{I} \mid(33.3)$ & $\mathrm{I}(3.0)$ & - \\
Fever & - & - & - & - \\
Hepatic functions & $\mathrm{I}(3.0)$ & - & - & - \\
\hline
\end{tabular}


Table 4 Comparison of current study with other reports on first-line chemotherapy regimens for metastatic ESCC

\begin{tabular}{|c|c|c|c|c|c|}
\hline Regimen & $\mathbf{N}$ & $\begin{array}{l}\text { ORR } \\
\text { (\%) }\end{array}$ & $\begin{array}{l}\text { PFS/TTP } \\
\text { (months) }\end{array}$ & $\begin{array}{l}\text { OS } \\
\text { (months) }\end{array}$ & Author \\
\hline Nab-PTX+DDP & 33 & 60.6 & 6.2 & 15.5 & Current study \\
\hline \multicolumn{6}{|l|}{$\mathrm{PTX}+\mathrm{CAP}$} \\
\hline Ist line & 12 & 75.0 & 5.23 & 14.3 & Yun et $\mathrm{a}^{26}$ \\
\hline 2nd line & 20 & 45.0 & 4.54 & 8.4 & \\
\hline CAP+DDP & 72 & 51.4 & 4.2 & 12.0 & Lee et $\mathrm{al}^{32}$ \\
\hline TXT+DDP+5-Fu & 39 & 66.6 & 7.0 & 13.0 & Takahashi et al ${ }^{27}$ \\
\hline$A D M+5-F u+D D P$ & 41 & 43.9 & NR & 10.2 & Honda et $\mathrm{al}^{33}$ \\
\hline PTX+NDP $(E S C C=46)$ & 48 & 41.7 & 6.1 & 11.5 & Cao et $\mathrm{al}^{28}$ \\
\hline PTX+NDP $($ ESCC $=33)$ & 36 & 43.6 & 6.1 & 10.3 & Gong et a ${ }^{29}$ \\
\hline $5-F u+D D P$ & 32 & 13.0 & 3.6 & 5.5 & Lorenzen et $\mathrm{al}^{34}$ \\
\hline 5-Fu+DDP+cetuximab & 32 & 19.0 & 5.9 & 9.5 & \\
\hline $\mathrm{OXA}+\mathrm{CAP}$ & 64 & 43.8 & 4.0 & 10.0 & Qin et $\mathrm{al}^{35}$ \\
\hline CAP+DDP & 45 & 57.8 & 4.7 & 11.2 & Lee et $\mathrm{al}^{36}$ \\
\hline PTX+DDP & 35 & 48.6 & 7.0 & 13.0 & Zhang et $\mathrm{al}^{30}$ \\
\hline \multicolumn{6}{|l|}{ TXT+DDP } \\
\hline ESCC & 10 & 40.0 & 4.3 & 6.9 & Laack et $\mathrm{a}^{31}$ \\
\hline EADC & 6 & 20.0 & & & \\
\hline
\end{tabular}

Abbreviations: 5-Fu, 5-fluorouracil; ADM, doxorubicin; CAP, capecitabine; DCR, disease control rate; DDP, cisplatin; EADC, esophageal adenocarcinoma; ESCC, esophageal squamous cell carcinoma; N, number; Nab-PTX, nanoparticle albumin-bound paclitaxel; NDP, nedaplatin; NR, not reported; ORR, objective response rate; OS, overall survival; OXA, oxaliplatin; PFS, progression-free survival; TTP, time to progression; TXT, docetaxel; PTX, paclitaxel.

from 5.5 months to 14.3 months. Although, in the current study, the ORR and PFS were similar to those of other studies, a longer median OS, of 15.5 months, was observed. ECOG PS of patients, mild side effects of the regimen, and subsequent treatments for most patients $(87.9 \%$ patients receiving subsequent treatment after progression) may have contributed to better OS in our study. Moreover, the favorable safety profile and greater median OS may be partially explained by higher intracellular delivery of PTX through the albumin-based nanoparticle technology and its utilization of the glycoprotein (gp)60-caveolin1-secreted protein acidic and rich in cysteine (SPARC) pathway across the endothelial barrier. ${ }^{13,37,38}$ SPARC, an albumin-binding protein, is overexpressed and secreted in many cancers and is a prognostic factor for poor survival in a number of tumor types. The gp60-mediated endothelial cell transcytosis of albumin-bound PTX and subsequent albumin binding to SPARC enhances the penetration of Nab-PTX into the tumor interstitium, thus PTX accumulation in tumor was greater for Nab-PTX compared with traditional PTX in tumor mouse models. ${ }^{13,37,38}$

Several studies ${ }^{19,20,39-41}$ have investigated Nab-PTX as a single agent or in combination in breast cancer, NSCLC, and pancreatic cancer. Nab-PTX always showed high efficacy and was well tolerated when combined with capecitabine, bevacizumab, gemcitabine, carboplatin, and trastuzumab, respectively. Our study reported that Nab-PTX plus DDP showed high activity and mild side effects in metastatic ESCC. Although it is difficult to draw the conclusion that the Nab-PTX plus DDP regimen is better than other regimens, considering the small sample size and lack of control arm, this regimen could be a good option and deserves further investigation as first-line chemotherapy for metastatic ESCC.

\section{Conclusion}

The combination of a new formulation, Nab-PTX, and DDP, seems to be a highly effective and well-tolerated first-line regimen for metastatic ESCC. The rate of grade 3-4 toxicities was very low. Further prospective randomized clinical trials with a larger sample size are necessary to obtain more evidence to determine the efficacy and safety of Nab-PTX and DDP for metastatic ESCC.

\section{Author contributions}

All authors contributed substantially to the study. Yan Shi contributed to the design of the study, recruitment of patients, data analysis, and writing and revision of the manuscript. Rui Qin and Zhi-Kuan Wang contributed to patient recruitment, collection, acquisition and analysis of data as well as writing and revision of the manuscript. Guang-Hai Dai contributed to design of the study, critical revision of the manuscript, and financial support prior to publication. All authors read and approved the final manuscript. 


\section{Acknowledgments}

This work was supported by Medical Project of Jie-Ping Wu Fund of China (Guang-Hai Dai, 320.6750.1233). The authors wish to acknowledge all the staff at the study center who contributed to this study. We are also grateful to the Department of Multimodality Therapy of Oncology and Department of Medical Oncology at CPLA General Hospital.

\section{Disclosure}

The authors report no conflicts of interest in this work.

\section{References}

1. Jemal A, Siegel R, Xu J, Ward E. Cancer statistics, 2010. CA Cancer J Clin. 2010;60(5):277-300.

2. Siewert JR, Stein HJ, Feith M, Bruecher BL, Bartels H, Fink U. Histologic tumor type is an independent prognostic parameter in esophageal cancer: lessons from more than 1,000 consecutive resections at a single center in the Western world. Ann Surg. 2001;234(3):360-369.

3. Iizuka T, Kakegawa T, Ide H, et al. Phase II evaluation of cisplatin and 5-fluorouracil in advanced squamous cell carcinoma of the esophagus: a Japanese esophageal oncology group trial. Jpn J Clin Oncol. 1992; 22(3):172-176.

4. Albertsson M, Johansson B, Friesland S, et al. Phase II studies on docetaxel alone every third week, or weekly in combination with gemcitabine in patients with primary locally advanced, metastatic, or recurrent esophageal cancer. Med Oncol. 2007;24(4):407-412.

5. Petrasch S, Welt A, Reinacher A, Graeven U, König M, Schmiegel W. Chemotherapy with cisplatin and paclitaxel in patients with locally advanced, recurrent or metastatic oesophageal cancer. Br J Cancer. 1998;78(4):511-514.

6. Cunningham D, Starling N, Rao S, et al. Capecitabine and oxaliplatin for advanced esophagogastric cancer. N Engl J Med. 2008;358(1):36-46.

7. Wang H, Ryu J, Gandara D, et al. A phase II study of paclitaxel, carboplatin, and radiation with or without surgery for esophageal cancer. J Thorac Oncol. 2007;2(2):153-157.

8. Kim JY, Do YR, Park KU, et al. A multi-center phase II study of docetaxel plus cisplatin as first-line therapy in patients with metastatic squamous cell esophageal cancer. Cancer Chemother Pharmacol. 2010; 66(1):31-36.

9. Van Cutsem E, Moiseyenko VM, Tjulandin S, et al; V325 Study Group. Phase III study of docetaxel and cisplatin plus fluorouracil compared with cisplatin and fluorouracil as first-line therapy for advanced gastric cancer: a report of the V325 Study Group. J Clin Oncol. 2006;24(31):4991-4997.

10. Overman MJ, Kazmi SM, Jhamb J, et al. Weekly docetaxel, cisplatin, and 5-fluorouracil as initial therapy for patients with advanced gastric and esophageal cancer. Cancer. 2010;116(6):1446-1453.

11. Tebbutt NC, Cummins MM, Sourjina T, et al; Australasian GastroIntestinal Trials Group. Randomised, non-comparative phase II study of weekly docetaxel with cisplatin and 5-fluorouracil or with capecitabine in oesophagogastric cancer: the AGITG ATTAX trial. Br J Cancer. 2010;102(3):475-481.

12. Green MR, Manikhas GM, Orlov S, et al. Abraxane, a novel Cremophor-free, albumin-bound particle form of paclitaxel for the treatment of advanced non-small-cell lung cancer. Ann Oncol. 2006;17(8): 1263-1268.

13. Desai N, Trieu V, Yao Z, et al. Increased antitumor activity, intratumor paclitaxel concentrations, and endothelial cell transport of cremophorfree, albumin-bound paclitaxel, ABI-007, compared with cremophorbased paclitaxel. Clin Cancer Res. 2006;12(4): 1317-1324.

14. Montana M, Ducros C, Verhaeghe P, Terme T, Vanelle P, Rathelot P. Albumin-bound paclitaxel: the benefit of this new formulation in the treatment of various cancers. J Chemother. 2011;23(2):59-66.
15. Gradishar WJ, Tjulandin S, Davidson N, et al. Phase III trial of nanoparticle albumin-bound paclitaxel compared with polyethylated castor oil-based paclitaxel in women with breast cancer III trial. J Clin Oncol. 2005;23(31):7794-7803.

16. Von Hoff DD, Ramanathan RK, Borad MJ, et al. Gemcitabine plus nab-paclitaxel is an active regimen in patients with advanced pancreatic cancer: a phase I/II trial. J Clin Oncol. 2011;29(34): 4548-4554.

17. Socinski MA, Manikhas GM, Stroyakovsky DL, et al. A dose finding study of weekly and every-3-week nab-Paclitaxel followed by carboplatin as first-line therapy in patients with advanced non-small cell lung cancer. J Thorac Oncol. 2010;5(6):852-861.

18. Oken MM, Creech RH, Tormey DC, et al. Toxicity and response criteria of the Eastern Cooperative Oncology Group. Am J Clin Oncol. 1982; 5(6):649-655.

19. Therasse P, Arbuck SG, Eisenhauer EA, et al. New guidelines to evaluate the response to treatment in solid tumors. J Natl Cancer Inst. 2000; 92(3):205-216.

20. National Cancer Institute: Common Terminology Criteria for Adverse Events version 3.0. (CTCAE). http://ctep.cancer.gov/reporting/ctc_v30. html.

21. National Comprehensive Cancer Network Guidelines in Oncology. Esophageal cancer. Available at: http://www.nccn.org.

22. Homs MY, v d Gaast A, Siersema PD, Steyerberg EW, Kuipers EJ. Chemotherapy for metastatic carcinoma of the esophagus and gastro-esophageal junction. Cochrane Database Syst Rev. 2006;4: CD004063.

23. Siewert JR, Ott K. Are squamous and adenocarcinomas of the esophagus the same disease? Semin Radiat Oncol. 2007;17(1):38-44.

24. Dreilich M, Wanders A, Brattström D, et al. HER-2 overexpression (3+) in patients with squamous cell esophageal carcinoma correlates with poorer survival. Dis Esophagus. 2006;19(4):224-231.

25. Li QQ, Liu MZ, Hu YH, Liu H, He ZY, Lin HX. Definitive concomitant chemoradiotherapy with docetaxel and cisplatin in squamous esophageal carcinoma. Dis Esophagus. 2010;23(3):253-259.

26. Yun T, Han JY, Lee JS, et al. Phase II study of weekly paclitaxel and capecitabine in patients with metastatic or recurrent esophageal squamous cell carcinoma. BMC Cancer. 2011;11:385.

27. Takahashi H, Arimura Y, Yamashita K, et al. Phase I/II study of docetaxel/cisplatin/fluorouracil combination chemotherapy against metastatic esophageal squamous cell carcinoma. JThorac Oncol. 2010; 5(1):122-128

28. Cao W, Xu C, Lou G, et al. A phase II study of paclitaxel and nedaplatin as first-line chemotherapy in patients with advanced esophageal cancer. Jpn J Clin Oncol. 2009;39(9):582-587.

29. Gong Y, Ren L, Zhou L, et al. Phase II evaluation of nedaplatin and paclitaxel in patients with metastatic esophageal carcinoma. Cancer Chemother Pharmacol. 2009;64(2):327-333.

30. Zhang X, Shen L, Li J, Li Y, Li J, Jin M. A phase II trial of paclitaxel and cisplatin in patients with advanced squamous-cell carcinoma of the esophagus. Am J Clin Oncol. 2008;31(1):29-33.

31. Laack E, Andritzky B, Dürk H, et al. Docetaxel and cisplatin as first-line treatment for patients with metastatic esophageal cancer: a pilot study. Onkologie. 2005;28(12):647-650.

32. Lee S, Park YH, Kim KH, et al. Thymidine synthase, thymidine phosphorylase, and excision repair cross-complementation group 1 expression as predictive markers of capecitabine plus cisplatin chemotherapy as first-line treatment for patients with advanced oesophageal squamous cell carcinoma. Br J Cancer. 2010;103(6): 845-851.

33. Honda M, Miura A, Izumi Y, et al. Doxorubicin, cisplatin, and fluorouracil combination therapy for metastatic esophageal squamous cell carcinoma. Dis Esophagus. 2010;23(8):641-645.

34. Lorenzen S, Schuster T, Porschen R, et al. Cetuximab plus cisplatin-5fluorouracil versus cisplatin-5-fluorouracil alone in first-line metastatic squamous cell carcinoma of the esophagus: a randomized phase II study of the Arbeitsgemeinschaft Internistische Onkologie. Ann Oncol. 2009; 20(10):1667-1673. 
35. Qin TJ, An GL, Zhao XH, et al. Combined treatment of oxaliplatin and capecitabine in patients with metastatic esophageal squamous cell cancer. World J Gastroenterol. 2009;15(7):871-876.

36. Lee J, Im YH, Cho EY, et al. A phase II study of capecitabine and cisplatin (XP) as first-line chemotherapy in patients with advanced esophageal squamous cell carcinoma. Cancer Chemother Pharmacol. 2008;62(1):77-84.

37. Gradishar WJ. Albumin-bound paclitaxel: a next-generation taxane. Expert Opin Pharmacother. 2006;7(8):1041-1053.

38. Desai NP, Trieu V, Hwang LY, Wu R, Soon-Shiong P, Gradishar WJ. Improved effectiveness of nanoparticle albumin-bound (nab) paclitaxel versus polysorbate-based docetaxel in multiple xenografts as a function of HER2 and SPARC status. Anticancer Drugs. 2008;19(9):899-909.
39. Schwartzberg LS, Arena FP, Mintzer DM, Epperson AL, Walker MS Phase II multicenter trial of albumin-bound paclitaxel and capecitabine in first-line treatment of patients with metastatic breast cancer. Clin Breast Cancer. 2012;12(2):87-93.

40. Link JS, Waisman JR, Nquyen B, Jacobs CI. Bevacizumab and albuminbound paclitaxel treatment in metastatic breast cancer. Clin Breast Cancer. 2007;7(10):779-783.

41. Mirtsching B, Cosgriff T, Harker G, Keaton M, Chidiac T, Min M. A phase II study of weekly nanoparticle albumin-bound paclitaxel with or without trastuzumab in metastatic breast cancer. Clin Breast Cancer. 2011;11(2):121-128.

\section{Publish your work in this journal}

OncoTargets and Therapy is an international, peer-reviewed, open access journal focusing on the pathological basis of all cancers, potential targets for therapy and treatment protocols employed to improve the management of cancer patients. The journal also focuses on the impact of management programs and new therapeutic agents and protocols on

\section{Dovepress}

patient perspectives such as quality of life, adherence and satisfaction The manuscript management system is completely online and includes a very quick and fair peer-review system, which is all easy to use. Visit http://www.dovepress.com/testimonials.php to read real quotes from published authors.

Submit your manuscript here: http://www.dovepress.com/oncotargets-and-therapy-journal 